\title{
Consumer behaviour and contraceptive decisions: resolving a decades-long puzzle
}

\author{
Martha Campbell
}

\section{Introduction}

Demographers' theoretical explanations for fertility decline have been based for decades on an assumption that couples make family size decisions influenced by a changing balance between costs and benefits of childbearing, resulting in parents' reduced demand for children. ${ }^{1-3}$ It has been widely assumed that these decisions are based on changes in social or economic factors, such as increased education, wealth or economic opportunities, or urbanisation, or other related factors in their lives. However, a number of situations in developing countries have been documented showing that contraceptive prevalence rose more rapidly than such theories could account for. In some instances desired family size changed when contraception became available, and in others women who said they did not want to use contraception adopted a method when the option to use it arrived. We have reviewed the cases of this kind that are published in the demographic literature, and we offer a plausible explanation grounded in research on consumer behaviour.

\section{Mystery contraceptors}

The following situations have in common either changes in desired family size or rapid uptake of contraception that cannot be explained in the dominant theoretical framework.

In Pakistan, six household contraceptive distribution projects covering an aggregate of 15000 married women resulted in a rise in the use of modern contraceptives from a baseline average of $12 \%$ for all six projects to $33 \%$ after 1 year. ${ }^{4}$ In Bangladesh, the percentage of women with two children who wanted no more children or chose sterilisation rose from $48 \%$ in 1991 to $66 \%$ in 1999-2000, even though $59 \%$ of women aged 15 to 24 years remained illiterate. ${ }^{5}$ In an 8 -year study in West Bengal, India, when family welfare assistants were trained to take contraceptive choices to women's homes, the contraceptive prevalence rate (CPR) in Sirajganj rose from $9 \%$ to $40 \%$, and in Abhoynagar from $27 \%$ to $46 \%$. Using quantitative and qualitative criteria, Chacko concluded that the availability of government health services influenced the use of modern contraceptives in these settings. ${ }^{6}$ In Morocco, a 1995 panel survey following the 1992 Demographic and Health Survey II, with data for 910 women, showed that approximately 30\% of those women who reported in 1992 that they did not intend to use a contraceptive in the future were actually using a method in the 1995 survey.7

In operations research in El Quiche, Guatemala, favourable attitudes towards contraception increased when services were tailored to the needs of the Mayan communities, including the number of service delivery points with personnel able to speak the local language and

J Fam Plann Reprod Health Care 2006; 32(4): 241-244

(Accepted 16 August 2006)

School of Public Health, University of California, Berkeley, CA, USA

Martha Campbell, PhD, Lecturer

Correspondence to: Dr Martha Campbell, School of Public Health, 506 Warren Hall, University of California, Berkeley, CA 94720-7360, USA. E-mail: campbell@berkeley.edu the number of family planning methods available. ${ }^{8}$ In further analysis of two decades of contraceptive dynamics in Guatemala, socioeconomic variables explained only about $25 \%$ of significant increases in contraceptive use. ${ }^{9}$

In a pilot study in Ishan, Nigeria between 1969 and 1972 , the percentage of women who wanted to limit their family size rose from $28 \%$ to $57 \%$, the CPR jumped from $1 \%$ to 24 , and the percentage of women who said they did not want to limit family size dropped from $54 \%$ to $14 \%$. The authors attributed all of these changes to the introduction of family planning. ${ }^{10}$ Two decades later Freedman commented: "Unfortunately, the year-by-year increases in annual surveys in proportions of women wanting to limit family size are too great to be credible for such a short period: 1969, 28 percent; 1970, 36 percent; 1971, 43 percent; and 1972, 57 percent", 11 and he went on to speculate that perhaps the women were exaggerating to please the investigators. However, there is an even more dramatic example of rapid increase in CPR following easy access. When contraceptives were offered to Cambodian refugees living in the Khao-I-Dang camp in eastern Thailand in 1980, virtually all the women had not even seen a modern method of contraception, yet the CPR jumped from zero prevalence to $52 \%$ of married women using contraceptives within 1 month. ${ }^{12}$ In a neighbouring camp, Sakaew, within 3 days 2252 out of 10000 married women sought family planning advice. In 1 week contraceptive prevalence had jumped more than it had climbed in most countries in a generation. ${ }^{13}$

\section{Normal consumer behaviour}

The long-respected demand-oriented theories, as noted, do not explain the decision-making revealed in the examples above, where women have chosen to use contraception or to have a small family only after family planning became realistically available. These examples do, however, fit normal consumer behaviour. In 1966, Rex Campbell defined two decision processes in the adoption of consumer goods: the rational problem-solving process, when the consumer becomes aware of the problem and then looks for a solution; and rational innovation, when the consumer becomes aware of the innovation before he or she recognises the problem. ${ }^{14}$ In 1983, Everett Rogers published his description of how innovations are diffused throughout a market or society. He observed: "An individual may develop a need when he or she learns that an innovation exists. Therefore, innovations can lead to needs as well as vice versa". 15

When companies were first invited to try out one of the original Xerox ${ }^{\mathrm{TM}}$ machines on site, they thought they might have some small uses for it, but within weeks had made thousands of copies. Post-it ${ }^{\mathrm{TM}}$ Notes, personal computers, Palm Pilots ${ }^{\mathrm{TM}}$, TV remote controls, garage door openers, Cuisinart food processors, disposable nappies and automatic teller machines are all examples of products we never knew we wanted until they appeared. Even though it is easy for us to relate the consumer behaviour theories to broad aspects of our daily lives, these findings have not been applied systematically to analyses of family planning.

One more element is needed to draw the connection between consumer behaviour and family planning decisions. It is the idea of costs, which in the consumer 
world are typically financial, while in family planning the costs come in many forms because of special barriers to availability.

\section{Barriers and their consequences}

Barriers standing between women and the option of regulating their fertility exist at many levels throughout the developing world - and even to some extent in the USA. The first comprehensive review of the wide range of these barriers has recently been published, ${ }^{16}$ focusing on lowincome women in developing countries. The types of barriers include the status of women, geographic access, financial barriers, medical rules and restrictions, shortfalls and breaks in commodity supplies, contraceptive side effects, misinformation, and laws restricting the provision of safe abortion.

Financial costs and geographic distance from contraceptive services are the simplest barriers. Medical barriers are more complex and come in many forms. That they prevent women from having access to family planning is often not intended by the governments or medical associations that have established them. Examples of medical barriers are requirements that a woman must be menstruating when she seeks contraception at a clinic, ${ }^{17}$ or that she must have medical examinations or laboratory tests she cannot afford. Women seeking sterilisation are often denied this option or the surgery is severely delayed. ${ }^{18}$ Provider bias is also common in many countries, setting up their own barriers such as asking women if they had permission from their husbands, ${ }^{19}$ or refusing to provide contraception to nulliparous women.

A major but more subtle form of barriers is misinformation. Survey data show that women in many countries are fearful of contraception because of side effects, including negative health impacts such as disease or threatening future fertility. A study of eight developing countries showed that $50-70 \%$ of women thought that the use of pills was a considerable health risk. ${ }^{20}$ When we recognise that the perceived health impacts represent misinformation, then it is easier for us to understand why many women do not believe they have any option to control their fertility. In this situation their decision not to use contraception is a rational one, given the information they have available.

\section{Availability leads to contraceptive use}

Also, once we understand the scale and number of the barriers to fertility regulation methods, we can more easily understand how their sudden absence can result in rapid increases in contraceptive use. Returning to the example of rapid increase in CPR in Ishan, Nigeria, we should not hastily dismiss the possibility Freedman raises that the data might reflect survey responses designed to please the investigators. But we should also not dismiss as impossible or unlikely the reported rapid rise in CPR. When we keep in mind normal consumer behaviour around other goods and services, data such as Farooq and Adeokun's in Nigeria seem more plausible. ${ }^{10}$ The examples quoted from the Cambodian refugee camps in Thailand ${ }^{12}$ support the possibility of such rapid change when contraceptives first become realistically available.

Long-term research in Matlab, Bangladesh has provided much evidence of the influence of realistic availability on the demand for family planning. One longitudinal study ending in 1979 found that $25 \%$ of the 733 respondents who originally did not intend to use contraception were in fact using it 4 months later. ${ }^{21}$ Later in Matlab, when injectable contraceptives were delivered to the women's homes, the CPR rose from $7 \%$ to $20 \%$ in 3 months. It jumped another ten percentage points when tubectomy services were offered in a Matlab Bazaar clinic in 1978, and climbed yet again when household-based intrauterine device (IUD) insertions were provided. ${ }^{22}$ Family size declined 25\% more rapidly in Matlab than in control areas, and some authors ascribe this difference to the availability of the injectable contraceptive, depot medroxyprogesterone acetate. ${ }^{23,24}$

More generalised analyses have been consistent with these findings in Bangladesh. One important study has shown that increasing the number of contraceptive methods available in a country increased the overall practice of contraception. ${ }^{25}$ A decade earlier, a study of five countries (Taiwan, South Korea, Thailand, Hong Kong and India) had shown that each new method of contraception offered in a national family planning programme resulted in a net increase in contraceptive prevalence in each of these countries. ${ }^{26}$

\section{Searching for answers}

In the Morocco situation noted, Curtis and Westoff, recognising that education explains only part of the reversal in women's decisions, looked carefully at the social environment where the total fertility rate (TFR) in 1992 was 4 and CPR among married women was $20 \%$. These authors suggested: "women in societies, or in subgroups of the population in which contraceptive use is widespread, may find it easier to act on their contraceptive intentions, particularly if they are weakly held, than women in societies or communities in which contraceptive use is less common". ${ }^{27}$ A new analysis 3 years later by Magnani et al. suggested that the most plausible explanation "would seem to be a supply-side effect on both contraceptive intentions and subsequent use". 7 They noted: "Women who resided in areas with a favorable family planning supply environment were substantially more likely to have gone on to use a contraceptive method during the three-year study period between the two surveys than were women less favorably situated with regard to family planning services, regardless of their contraceptive intentions at the time of the 1992 survey". 7

The common factor we see in these examples is the ease of access to, or realistic availability of, the contraceptive technologies (products or services) for women to have control over whether and when to have a child, including correct information to make them useful.

\section{Impacts of realistic options}

Between 1990 and 2000, the TFR in Addis Ababa, Ethiopia fell from 3.1 to $1.8 .^{28}$ Among the poorest capitals in Africa, Addis Ababa's fertility decline was not predicted by any demographer or sociologist. As recently as 1990, "Ethiopia was not considered among the countries at or near the start of the transition to low fertility". 29 Data are emerging to support the hypothesis that ease of access to contraception and safe abortion is the most plausible primary engine driving the rapid fertility decline. In 2005, Marie Stopes centres in Addis Ababa provided reproductive health services to 85000 clients. In the same year, Ethiopia reformed its abortion law and data on abortion numbers became more available. Over 30000 manual vacuum aspiration (MVA) comprehensive abortion care procedures were done in 2005 in Addis Ababa, each one followed up with contraception and advice. Given the scale of these services, it seems plausible that their presence has led to a broad understanding by women and couples throughout the city that there are safe options for managing fertility.

In Bali, Indonesia in the 1970s, a senior gynaecologist (now deceased) offered MVA early abortion to women who 
chose an IUD if they were to become pregnant. This assurance was extended later to any woman using a modern method of contraception. There is good evidence that the availability of safe abortion can improve the adoption and continuation of contraception. ${ }^{30}$ The TFR in Bali fell rapidly from 6 in 1970 to 2.1 in 1994, and today the island of Bali continues to have the lowest TFR in the country. ${ }^{31}$

The changes in the Islamic Republic of Iran are particularly striking. In 1986, Iranian economists recognised that the population was growing faster than the economy, implying increasing poverty in the future. In 1987, the religious leadership accepted a policy initiative of the Ministry of Health to make available a full range of contraceptive choices, including voluntary male and female sterilisation. Condom and pill factories were built and all engaged couples were required to receive family planning instruction. Community health workers carried family planning into the rural areas. This voluntary programme was associated with one of the most rapid declines in TFR ever recorded, from a TFR of 5.5 in 1987 to 2.0 in 2000 . Remarkably, the higher TFR seen in rural areas in 1977 ( 3.5 births) narrowed to 0.5 births in 2000.32 Iran did not reform the abortion law, but both medical and surgical abortions do seem to be available, at least to some women. There were no concomitant large changes in socioeconomic factors. The fertility decline does correlate with a decrease in maternal and infant mortality and a rapid increase in tertiary education for women but it is as plausible that these were driven by the declining fertility as vice versa.

South Korea and Cuba are poles apart in culture, religion and economic profiles, and their family planning programmes were developed for different reasons: the Cuban for health reasons and the Korean for demographic objectives, as they saw smaller families were required for the country to escape from poverty. However, between 1960 and 1990, the TFR in both countries followed a similar trajectory, as their respective governments offered couples modern contraceptive choices and safe abortion. ${ }^{33}$ It is contradictory to argue that Korea's demographic change is due to its economic growth (although it actually began before the economy took off), while Cuba's identical change occurred because of a deteriorating economic environment. It is more reasonable to conclude that the common factor linking similar fertility declines in these two extremely different socioeconomic environments was the ease of access to fertility regulation methods, including both family planning and safe abortion.

All of these examples imply influence of realistic availability of safe options for managing fertility on contraceptive prevalence. Interestingly, while demandoriented models are most widely accepted as theoretical explanations for fertility decline, in reality most family planning programmes over the decades have been supplyoriented, ${ }^{34-36}$ partly because of an assumption that better services have a positive impact on demand.

\section{Conclusions}

Caldwell has reminded us that without realistic contraceptive options, people may not have an opinion on the size of their families nor on whether to attempt to have control over childbearing. In a broad review of the demographic transition, Caldwell writes: "For forty years we have been asking, in surveys and one-on-one anthropological investigations in sub-Saharan Africa, rural South India, and rural Bangladesh, both of contraceptive users and nonusers, whether their parents used contraption or worried about the inability to control family size. The answers have been the same. The parents had not practiced birth control because they had no access to services. They had never contemplated restricting family size because, without the methods for doing so, it was unimaginable" 37 [italics added by present author].

Given the wide range of barriers to family planning in many developing countries, and the high prevalence of belief in high fertility settings that family planning is unsafe, and even more dangerous than another pregnancy, it should not be surprising that demand for contraception changes when correct information arrives with the needed technologies - in keeping with normal consumer behaviour. In many of today's countries with persistently high fertility, contraceptive commodities are in short supply, the extent and range of barriers are not yet well understood by governments, and misinformation is often stifling demand in the lowest resource settings. Rectifying these three factors inhibiting contraceptive use would go a long way to improving the health and well-being of women and their families.

\section{Statements on funding and competing interests}

Funding. None identified.

Competing interests. None identified.

\section{Acknowledgement}

The author is grateful to Rebekah Saul Butler, MPH, MBA, for her research for this project on consumer behaviour in the Haas School of Business, University of California, Berkeley, CA, USA

References

1 Leibenstein HM. Economic Backwardness and Economic Growth. New York, NY: John Wiley \& Sons, 1957.

2 Becker GS. An economic analysis of fertility. Demographic and Economic Change in Developed Countries. Princeton, NJ: National Bureau of Economic Research, 1960.

3 Cleland J, Wilson C. Demand theories of the fertility transition: an iconoclastic view. Popul Stud 1987; 41: 5-30.

4 Shelton JD, Bradshaw L, Hussein B, Zubair Z, Drexler T, McKenna MR. Putting unmet need to the test: community-based distribution of family planning in Pakistan. Int Fam Plan Perspect 1999; 25: 191-195.

5 Population Reference Bureau. Women of Our World 2005. Washington, DC: Population Reference Bureau, 2005.

6 Chacko E. Women's use of contraception in rural India: a villagelevel study. Health Place 2001; 7: 197-208.

7 Magnani RJ, Hotchkiss DR, Florence CS, Shafer LA. The impact of family planning supply environment on contraceptive intentions and use in Morocco. Stud Fam Plann 1999; 30: 120-132.

8 Bertrand JT, Guerra de Salazar S, Mazariegos L, Salanic V, Rice J, Sow CK. Promoting birthspacing among the Maya-Quiche of Guatemala. Int Fam Plan Perspect 1999; 25: 160-167.

9 Bertrand JT, Seiber E, Escudero G. Contraceptive dynamics in Guatemala: 1978-1998. Int Fam Plan Perspect 2001; 27: 112-136.

10 Farooq GM, Adeokun LA. Impact of rural family planning program in Ishan, Nigeria, 1969-72. Stud Fam Plann 1976; 7: 158-169.

11 Freedman R. Do family planning programs affect fertility preferences? A literature review. Stud Fam Plann 1997; 28: 1-13.

12 D'Agnes T. From Condoms to Cabbages: The Authorized Biography of Mechai Viravaidya. Bangkok, Thailand: The Bangkok Publishing Public Company Ltd, 2001.

13 Potts M. Refugees - even those fleeing from genocide - do not want to start families. People 1980; 7: 28-29.

14 Sheth J. Models of Buyer Behavior. New York, NY: Harper \& Row, 1974.

15 Rogers E. Diffusion of Innovations (3rd edn). New York, NY: The Free Press, 1983; 166.

16 Campbell M, Sahin-Hodoglugil NN, Potts M. Barriers to fertility regulation: a review of the literature. Stud Fam Plann 2006; 37: 87-98.

17 Stanback J, Thompson A, Hardee K, Janowitz B. Menstruation requirements: a significant barrier to contraceptive access in developing countries. Stud Fam Plann 1997; 28: 245-250.

18 Lassner KJ, Janowitz B, Rodrigues CM. Sterilization approval and follow-through in Brazil. Stud Fam Plann 1986; 17: 188-198.

19 Tomeczuk B. Summary from a reproductive health survey among Afghan refugees in Pakistan. Unpublished Technical Report, 2000.

20 Grubb GS. Women's perception of the safety of the pill: a survey in eight developing countries. J Biosoc Sci 1987; 19: 313-321.

21 Bhatia $S$. Contraceptive intentions and subsequent behavior in rural Bangladesh. Stud Fam Plann 1982; 13: 24-31.

22 Phillips JF, Simmons R, Koenig MA, Chakraborty J. Determinants of 
reproductive change in a traditional society: evidence from Matlab, Bangladesh. Stud Fam Plann 1988; 19: 313-334.

23 Caldwell P, Caldwell J. What does the Matlab fertility experience really show? Stud Fam Plann 1992; 23: 292-310.

24 Haaga JG, Maru RM. The effect of operations research on program changes in Bangladesh. Stud Fam Plann 1991; 27: 76-87.

25 Jain A. Fertility reduction and the quality of family planning services. Stud Fam Plann 1989; 20: 1-16.

26 Freedman R, Berelson B. The record of family planning programs. Stud Fam Plann 1976; 7: 3

27 Curtis, SL, Westoff CF. Intention to use contraceptives and subsequent contraceptive behavior in Morocco. Stud Fam Plann 1996; 27: 239-250.

28 Central Statistical Authority (Ethiopia) and ORC Macro. Ethiopia Demographic and Health Survey 2000. Addis Ababa, Ethiopia and Calverton, MD: Central Statistical Authority and ORC Macro, 2001.

29 Sibanda A, Woubalem Z, Hogan DP, Lindstrom DP. The proximate determinants of the decline to below-replacement fertility in Addis Ababa, Ethiopia. Stud Fam Plann 2003; 34: 1-7.
30 Potts M, Diggory P, Peel J. Abortion. Cambridge, UK: Cambridge University Press, 1970.

31 Potts M. Sex and the birth rate: human biology, demographic change, and access to fertility-regulation methods. Popul Dev Rev 1997; 23: $1-39$.

32 Iranian Ministry of Health and Medical Education. Demographic and Health Survey Iran 2000. Tehran, Iran: Ministry of Health, 2002.

33 Noble J, Potts M. The fertility transition in Cuba and the Federal Republic of Korea: the impact of organized family planning. J Biosoc Sci 1996; 28: 211-225.

34 Ravenholt RT. AID's family planning program. Science 1969; 163: 124-127.

35 Freedman R, Berelson B. The record of family planning programs. Stud Fam Plann 1976; 7: 3-40.

36 Potts M, Campbell M. Reverse gear: Cairo's dependence on a disappearing paradigm. Reprod Contracept 2005; 16: 179-186.

37 Caldwell JC. The globalization of fertility behavior. In: Bulatao R, Casterline J (eds), Global Fertility Transition. New York, NY: Population Council, 2001; 93-115.

\section{Journal Review}

Factors predisposing women to chronic pelvic pain: systematic review. Latthe $P$, Mignini L, Gray R, Hills R, Khan K. BMJ 2006; 332: 749-755

This systematic review identified over 5500 citations and selected 122 studies to review, incorporating a cohort of almost 95000 women. Studies were grouped according to whether the study population's main complaint was dysmenorrhoea, dyspareunia, or non-cyclical pelvic pain. The authors evaluated more than 60 risk factors for chronic pain and identified a consistently complex multifactorial aetiology for each of these groups (prominent risk factors included the presence of pelvic pathology, history of abuse, and coexistent psychological morbidity).

The multifactorial aetiology confirms the benefit of a multidisciplinary approach to chronic pelvic pain with input from a gynaecologist with special interest and psychologists. However, it is important to note that studies investigating patients with irritable bowel syndrome as a comorbid condition were not included in the review. This is a group of patients who may present with chronic pelvic pain, and therefore a pelvic pain service should probably also involve a gastroenterologist.

Having identified the main aetiologies of chronic pelvic pain, the authors concluded that further research (in the form of randomised controlled trials) is required to evaluate the benefit of targeted management to potentially modifiable factors.

Reviewed by Philip Dutton, MB ChB

SHO3 in Obstetrics and Gynaecology, St John's Hospital, Scotland, UK

Incidence of severe reproductive tract complications associated with diagnosed genital chlamydial infection: the Uppsala Women's Cohort Study. Low N, Egger M, Sterne JAC, Harbard RM, Ibrahim F, Lindblom B, et al. Sex Transm Infect 2006; 82: 212-218

This large, retrospective, population-based cohort study provides convincing evidence that the incidence of severe complications associated with chlamydia infection is not as high as previously reported.

The study was set in Sweden, the first country to introduce a nationwide programme of opportunistic chlamydia screening. Over 43000 women aged between 15 and 24 years in one county were followed from 1985 to 1999 . During the 14 -year study period, $71 \%$ of women were screened for chlamydia and $13 \%$ had at least one episode of chlamydial infection. Using laboratory and hospital record linkage, the incidence of hospital-diagnosed pelvic inflammatory disease (PID), ectopic pregnancy and infertility was compared between woman who tested positive for chlamydia, tested negative and were never tested. Although a positive chlamydia result was consistently associated with increased complications, the difference was not as large as suggested by clinical studies. For example, the cumulative incidence for PID rose from $4.0 \%$ in those with a negative screen to only $5.6 \%$ in those who had a positive chlamydia result, and was $2.9 \%$ in those who were never screened. Low socioeconomic status was also shown to be associated with a marked increase in all complications.

While these results are reassuring for women, the authors claim that the costeffectiveness of chlamydia screening programmes may have been overestimated. To establish the true risks of chlamydial infection, future studies need to include PID diagnosed in primary care and to examine the implications of repeated episodes of infection.

Reviewed by Kate McNab, MB ChB

SHO3 in Obstetrics and Gynaecology, Royal Infirmary of Edinburgh, Edinburgh, UK

One-stop shop versus collaborative integration: what is the best way of delivering sexual health services? French RS, Coope CM, Graham A, Gerressu M, Salisbury C, Stephenson JM, et al. Sex Transm Infect 2006; 82: 202-206

The National Strategy for Sexual Health and HIV recommends integration of sexual health services, but what does integration actually mean and on what evidence is this recommendation based? French and colleagues reviewed the evidence that is currently available from experiences of integration in the UK and they interviewed key informants involved in developing the strategy document.

According to the paper, the theoretical benefits of a one-stop shop approach include convenience, better continuity of care, fewer provider contacts, less need for interagency referral and the potential for staff to extend roles. A combined service may be more holistic and better able to target those individuals who are not aware that they need the alternative service. In financial terms, savings may be made from cost sharing and avoidance of duplication but this remains to be proven.

Despite evidence that working within an integrated service improves staff motivation, concerns have been voiced about loss of specialist skills and clashes between contradictory service cultures. Other potential weaknesses include reduced funding for satellite services and increased appointment times.

The authors conclude that there is currently insufficient evidence to suggest that one-stop shops are any more or less effective than separate services that work collaboratively. Although the paper leaves important questions unanswered, it does provide a useful review of the different levels of integration, the various models of service structure, and the potential pitfalls and barriers to integration of sexual health services.

Reviewed by Louise Melvin, MRCOG, MFFP Subspecialty Trainee, Dean Terrace Family Planning and Well Woman Clinic, Edinburgh, UK

Risk of nonfatal venous thromboembolism with oral contraceptives containing norgestimate or desogestrel compared with oral contraceptives containing levonorgestrel. Jick SS, Kaye JA, Russmann S, Jick H. Contraception 2006; 73: 566-570

This is a nested case control study, based on information from PharMetrics, a USA-based company that records information on claims paid by managed care plans. The authors calculated relative risks of non-fatal venous thromboembolism (VTE) among 15-39-year-old current users of oral contraceptives (OCs) containing norgestimate with 35 ug ethinylestradiol (EE), desogestrel with $30 \mu \mathrm{g}$ EE or levonorgestrel with $30 \mu \mathrm{g} \mathrm{EE}$, both monophasic and triphasic preparations, during the period January 2000 to March 2005.

Based on 281 newly diagnosed idiopathic cases of VTE and 1055 controls, they found that the adjusted odds ratios for non-fatal VTE comparing norgestimate- or desogestrelcontaining OC users to users of levonorgestrel-containing OCs were 1.1 [95\% confidence interval (CI) $0.8-1.6]$ and 1.7 (95\% CI 1.1-2.4), respectively. The incidence rates of VTE were 30.6 (95\% CI 25.5-36.5), 53.5 (95\% CI 42.9-66.0) and 27.1 (95\% CI 21.1-34.3) per 100000 woman-years for users of norgestimate-, desogestrel- and levonorgestrel-containing OCs, respectively.

The database does not give information on height, weight, family history or smoking status, all of which have been shown to be highly relevant in such analyses. Thus, as in previous studies by this group, and others not able to control for these variables, the authors conclude there are differences in VTE incidences between the preparations, but cannot exclude confounding and bias by potential differences in these important parameters. Incidentally, this would not be apparent from the abstract, highlighting the danger of relying on information from abstracts, without reading the full paper.

Reviewed by Anne Szarewski, PhD, FFFP Clinical Consultant and Honorary Senior Lecturer, Cancer Research UK Centre for Epidemiology, Mathematics and Statistics, Wolfson Institute of Preventive Medicine, London, UK 